\title{
Comparison of hysterosalpingography and transvaginal hydrolaparoscopy in patients with tubal factor infertility: a prospective cohort study
}

\author{
Deniz Balsak ${ }^{1}$, Fatma Uysal ${ }^{2}$, Salih Sadık ${ }^{1}$, Ahmet Güler ${ }^{1}$, Şivekar Tınar ${ }^{1}$, Ömür Taşkın \\ ${ }^{1}$ Department of Obstetrics and Gynecology, MH Aegean Maternity, Teaching and Training Hospital, Izmir, Turkey \\ ${ }^{2}$ Department of Radiology, MH Aegean Maternity, Teaching and Training Hospital, Izmir, Turkey \\ ${ }^{3}$ Akdeniz University, IVF Center, Turkey
}

Videosurgery Miniinv 2014; 9 (2): 190-195

DOI: 10.5114/wiitm.2014.41055

\begin{abstract}
Aim: To evaluate the usefulness, diagnostic accuracy, and cost-effectiveness of transvaginal hydrolaparoscopy (THL) in infertile women with abnormal hysterosalpingogram (HSG) results without obvious pelvic pathology.

Material and methods: Thirty infertile women (age: 20-40 years) who had tubal pathology in HSG were enrolled in the study. All patients underwent THL instead of standard laparoscopy. A cost analysis was performed comparing HSG and THL methods.

Results: In comparison of the HSG of cases by considering the chromopertubation results by THL, the sensitivity and specificity of HSG were $85.1 \%$ and $56 \%$, respectively. The reasons for preferring standard laparoscopy rather than THL were: failure in accessing of Douglas $(n=3)$, insufficient monitoring of pelvis $(n=1)$, hydrosalpinx $(n=1)$, and intense peritubal adhesion $(n=1)$, which were $10 \%, 3 \%, 3 \%$, and $3 \%$, respectively. The complication rate was $3.8 \%$. Cost analysis of the procedures showed that the total cost of the THL group was $34.8 \%$ lower than the HSG group.

Conclusions: In the elective patients group, THL is more feasible than HSG. Transvaginal hydrolaparoscopy is effective, simple and safe, avoiding the cost, possible complications, time and postoperative patient discomfort compared to conventional laparoscopy.
\end{abstract}

Key words: transvaginal hydrolaparoscopy, hysterosalpingography, infertility, laparoscopy, cost-effectiveness analysis.

\section{Introduction}

Tubal and peritoneal pathology are among the most common infertility causes, with infertility being seen in approximately $30-35 \%$ of couples [1]. The two classic tests assessing tubal efficiency in infertile women are hysterosalpingography (HSG) and laparoscopy. Although the uterine cavity and tubal lumen can be monitored by HSG, tubo-ovarian and pelvic anatomy can be assessed by laparoscopy. While laparoscopy provides detailed information about pelvic anatomy, including adhesion, endometriosis and ovarian pathologies, HSG does not provide this information. Moreover, HSG is also a method that is painful, requires exposure to radiation and has infectious complications possibly affecting fertility at a rate of $3 \%[2,3]$. However, it is a cheap method that can be applied in the office environment and has treatment efficiency.

Transvaginal hydrolaparoscopy (THL) is a method that has been developed in recent years and that is 
applied through the vagina. The advantage of the method developed by Gordts et al. [4] is that the uterine cavity and the peritoneal space as well as chromopertubation and tubal patency can be assessed at a single stage in the same session. Adnexa, tubes, pelvic peritoneum, posterior wall of the uterus and Douglas cavity can be examined with this method and chromopertubation and hysteroscopy can also be performed at the same time. It is recommended to be used as the first stage in the assessment of an infertile couple [3]. Use of sedation anesthesia in the operation is another important advantage of the method [4].

\section{Aim}

We aimed to examine the diagnostic accuracy of HSG by comparing it with the THL method for patients in whom tubal factor infertility was detected in HSG and who did not have a pelvic surgical operation history. Also, we calculated the economic burden on the insurance system of both methods, in reference to the social security insurance of Turkey. As far as we know, this is the first cost-effectiveness report in the literature about THL.

\section{Material and methods}

Thirty consecutive patients aged 20-40 years who were seen in the Infertility Outpatient Clinic of the T.R.M.H. Aegean Maternity and Gynecology Training Hospital and had tubal factor (proximal tubal occlusion) in HSG were prospectively included in the study. For the study, patients who did not become pregnant in spite of regular sexual intercourse for at least 12 months, who had a normal hormonal profile and regular ovulatory menstrual cycles, normal male parameters as well as proximal tubal occlusion detected in HSG, were included. Subjects who had a pelvic surgical operation history, and suspected pelvic inflammation were excluded from the study. HSGs of the patients were performed by the infertility specialists in outpatient clinics. ransvaginal hydrolaparoscopy operations were performed by 3 different operators.

Approval was received from the ethics committee of our hospital. The operation to be performed on the patients was explained and their written consent was obtained.

All patients were laid down on the operating table in a dorsal lithotomy position under spinal anesthesia. The perineum and vagina were cleaned with antiseptic solution, $10 \%$ polyvinyl-pyrrolidone iodine complex (Batticon ${ }^{\circledR}$, Adeka), for surgical antisepsis. $1 \mathrm{~g}$ of cefazolin sodium IV was injected for all patients after they were asked whether they had a prophylactic antibiotic allergy. The posterior lip of the cervix was grasped with a tenaculum. A specially designed trocar system (Miniport, $2 \mathrm{~mm}$, Disposable Sleeve and Introducer, W/I, 171312, Minisite, Autosuture) was introduced into the abdominal cavity at 10-15 $\mathrm{mm}$ beneath the point at which the cervix inserted into the vaginal wall. It was tested with saline solution to ensure that it was correctly positioned in the abdominal cavity. The Veress needle was removed and a rigid optical system with an angle of $0^{\circ}$ was inserted. When the abdominal introduction was verified visually, constant irrigation was ensured by using ringer lactate solution during the rest of the operation by means of a $3.5 \mathrm{~mm}$ shaft system. All operations were video recorded for documentation. Rotation, lateralization of the scope and localization of the tubo-ovarian structures were determined. The ovary and then the ovarian fossa were identified and inspection of the ovarian surface was started. The isthmic ampullary tubal segment located beside the ovarian ligament was monitored. Inspection of the Douglas cavity and uterosacral ligaments was performed. Instillation of diluted methylene blue was made through an $8 \mathrm{~F}$ silicon Foley catheter inserted in the uterine cavity in order to determine the tubal patency if no pathology was detected, after the same operation was performed on the contralateral side. The passage of methylene blue through the ampulla and tubal ostium was monitored. Operative laparoscopy and laparotomy sets were made ready in the operating room to immediately use if any pathology was detected during the operation. It was planned to convert to operative laparoscopy in the same session or in the next session depending on the choice of the patient if any pathology requiring surgical operation was detected. The excess fluid was effused by trocar at the end of the operation.

\section{Results}

A total of 30 patients with a mean age of 29.5 $\pm 6.2(20-45)$ years were included. The infertility period and body mass index (BMI) were $5.0 \pm 4.4(1-17)$ years and $27 \pm 3.8(18-33) \mathrm{kg} / \mathrm{m}^{2}$, respectively. Eighty 
Table I. Sociodemographic data

\begin{tabular}{|lc|}
\hline Parameter & Results \\
\hline Age, mean \pm SD (range) [years] & $29.5 \pm 6.2(20-45)$ \\
\hline $\begin{array}{l}\text { Body mass index, mean } \pm \text { SD } \\
\text { (range) }\left[\mathrm{kg} / \mathrm{m}^{2}\right]\end{array}$ & $27 \pm 3.8(18-33)$ \\
\hline Primary infertile, $n(\%)$ & $24(80)$ \\
Secondary infertile, $n(\%)$ & $6(20)$ \\
\hline Years of infertility, mean \pm SD & $5.0 \pm 4.4(1-17)$ \\
(range) [years] & \\
\hline
\end{tabular}

Table III. Reasons for preferring standard laparoscopy rather than $\mathrm{THL}$

\begin{tabular}{|lcc|}
\hline Variable & Number & Percentage \\
\hline $\begin{array}{l}\text { Failure in introduction of } \\
\text { Douglas }\end{array}$ & $3 / 30$ & 10 \\
\hline Insufficient monitoring of pelvis & $1 / 30$ & 3.3 \\
\hline Hydrosalpinx & $1 / 30$ & 3.3 \\
\hline Intense peritubal adhesion & $1 / 30$ & 3.3 \\
\hline Total & $6 / 30$ & 20 \\
\hline
\end{tabular}

percent of the cases were primary infertile and $20 \%$ were secondary infertile (Table I).

Comparison of the chromopertubation results between HSG and THL as a golden standard and 2 tubes were separately assessed. The sensitivity and specificity of HSG were $85.1 \%$ and $56 \%$, respectively. The average operation time was $8 \mathrm{~min}$ and the average use of ringer lactate for monitoring the pelvis in $\mathrm{THL}$ was $350 \mathrm{cc}$. The patients were followed up for $12 \mathrm{~h}$ on average after the operation (Table II).

Standard laparoscopy was used in 6 cases in our study (20\%). Standard laparoscopy was performed due to failure in accessing the pouch of Douglas in 3 of 6 cases. These cases were due to insufficient monitoring of the pelvis $(n=1)$, suspected hydrosalpinx $(n=1)$ and presence of intense peritubal
Table II. THL operative data

\begin{tabular}{|lcc|}
\hline Parameter & Mean & Range \\
\hline $\begin{array}{l}\text { Operation time (THL), } \\
\text { mean } \pm \text { SD [min] }\end{array}$ & $8 \pm 1.8$ & $5-15$ \\
\hline $\begin{array}{l}\text { Ringer solution used in THL, } \\
\text { mean } \pm \text { SD [cc] }\end{array}$ & $350 \pm 33$ & $150-650$ \\
\hline $\begin{array}{l}\text { Time of stay at hospital, } \\
\text { mean } \pm \text { SD [h] }\end{array}$ & $16 \pm 4.2$ & $8 \mathrm{~h}-1$ week \\
\hline
\end{tabular}

adhesion $(n=1)$. It was seen that the case with suspected hydrosalpinx was actually not hydrosalpinx. Adhesions were removed in a case that had intense peritubal adhesions (Table III).

One case (3.8\%) in our study was taken under follow-up with suspected rectal perforation upon the liquid emission under rectal touch control after THL was performed. The patient was hospitalized (with general surgeon consultation) for 7 days and cefazolin $1 \mathrm{~g} \mathrm{IV}\left(\right.$ Sezol $^{\circledR} 1 \mathrm{~g}$ twice a day) and ornidazole 500 mg IV (Flagyl ${ }^{\circledR}$ once a day) were applied. Oral administration to the patient was ceased and parenteral fluid and nutrition supplement was provided for 2 days. Vital sign follow-up and daily leukocyte follow-up was performed 3 times a day. As there was no problem during the follow-ups, the patient was discharged at the end of 1 week. No finding related to the fistula was found in the control after 1 month. We performed a cost analysis according to the operation pricing of the Turkish Social Security Institution (SSI) after the operation [5] (Table IV).

The procedural costs for diagnostic laparoscopy (DIA LS), operative laparoscopy (OP LS), transvaginal hydrolaparoscopy (TVHL), and HSG were based on the Notice of Health Implementations of the Turkish Social Security Institution. Due to the health policies in Turkey, a fixed package price system is performed for invasive procedures (surgery + anesthesia + hospital stay during procedure + medical care costs + drug costs), which made it easier for us to do the cost analysis. Diagnostic laparoscopy $(n=30)$

Table IV. Cost-effectiveness analysis

\begin{tabular}{|lccc|}
\hline \multicolumn{3}{|c|}{ Total cost } \\
\hline HSG (68)30 = 2040 TL & DIA LS (273)24 =6552 TL & OP LS (509)6 = 3054 TL & $11640 \mathrm{TL}$ \\
\hline $\begin{array}{l}\text { TVHL(187)30 + complication } \\
\text { price (350 TL) }=5960 \mathrm{TL}\end{array}$ & OP LS (509)6 = 3054 TL & $9014 \mathrm{TL}$ \\
\hline
\end{tabular}

Operations prices were obtained from the Notice of Health Implementations of Turkish Social Security Institution. TL (Turkish Lira), Diagnostic laparoscopy (DIA LS): 273 TL, Operative laparoscopy (OP LS): 509 TL, Diagnostic hysteroscopy (same cost with TVHL): 187 TL, HSG: 25 TL + radio-contrast agent 50 cc (43 TL), Complication Price (IV antibiotics + hospitalization) www.sgk.gov.tr. 2010 Notice of Health Implementations (5). One United States Dollar: TL: 1.7 Turkish Liras 
was used for patients with pathology determined by HSG; operative laparoscopy $(n=6)$ was used for patients with pathology determined during the laparoscopic observation. We used the operative laparoscopy $(n=6)$ method for treatment of problems in the TVHL group. Cost analysis of procedures showed that the total cost of the TVHL group was $34.8 \%$ lower than the HSG group.

\section{Discussion}

Hysterosalpingography has been the main outpatient screening tool for a long time in infertility assessment, with a relatively high false positive rate of 0.39 [3] in the diagnosis-follow-up scheme. It is particularly important in determining proximal tubal occlusion. In more complex situations, HSG gives way to more invasive operations and costly procedures [6]. Accordingly, even for diagnostic purposes, every additional operation has complications, cost, workforce loss and even esthetic problems.

Transvaginal hydrolaparoscopy is a relatively new method that has claimed to minimize all these problems for observation of the pelvic organs of infertile cases. In this respect, many researchers have published articles indicating that THL is more enlightening and tolerable than HSG and less invasive and reliable than standard laparoscopy [7-12].

The concordance of THL and laparoscopy has been reported as being between $78 \%$ and $100 \%$ in a compilation of 187 diseases and 6 studies, one of which was prospective double blind [13]. In spite of this, there are several handicaps of THL in application. Obliterated pouch of Douglas, fixed retroverted uterus, pelvic inflammatory disease, vaginal infection, ovarian mass and situations in which vaginal operation is not possible are the contraindications reported. Application failures of THL due to retroverted uterus and adhesions have been reported to be between $5 \%$ and $10 \%$. A monitoring rate including both ovaries and tubes has been reported as $88.3 \%$ compared to $90 \%$ in our study [9-14]. The average operation time was 15 min in the same study, compared to $8 \mathrm{~min}$ in the present study.

In studies where HSG and THL are compared, it has been reported that THL is more effective in determining the actual pathology in the cases with suspected tubal pathology. Furthermore, the possibility of detecting adhesions, endometriotic focus or pelvic pathologies that cannot be detected by HSG is within the scope of the effectiveness of THL [3, 9-11, 14].

The sensitivity of HSG is moderate and the specificity of HSG is high in broad-based compilations. Its sensitivity and specificity are respectively $53 \%$ and $87 \%$ for any tubal pathology and $46 \%$ and $95 \%$ for bilateral tubal pathology $[15,16]$. Our study group was composed of cases with tubal pathology detected in HSG. The sensitivity of HSG was found to be $85.1 \%$, positive predictive value (PPV) $67.6 \%$, and negative predictive value (NPV) $77.7 \%$ when we considered the chromopertubation performed with THL as the gold standard (each tube was assessed separately). The false positivity rate of HSG was found to be $25 \%$ and the false negativity rate of HSG was found to be $22 \%$. We can say that THL is more effective than HSG in determining the actual problem when assessed with our studies, in addition to its possible role in limited treatment.

The biggest handicap of the THL operation is that the practicability of operative procedures is limited. It has been reported in different publications that THL decreases the need for standard laparoscopy at a rate between $50 \%$ and $60.6 \%[17,18]$. Transvaginal hydrolaparoscopy decreased the need for standard laparoscopy in $80 \%$ of our case series. This necessity was caused by failure in accessing the pouch of Douglas in 3 cases, intense adhesions in 3 cases, possible hydrosalpinx in one case and insufficient pelvic vision in 1 case.

Among the studies in which laparoscopy and THL have been compared, it has been reported that THL showed a concordance of over $90 \%$ with laparoscopy [9]. We performed a cost analysis for the two different methods (HSG and THL), both of which have been in use for the diagnosis and treatment of tubal factor infertility. Operation prices were obtained from the Notice of Health Implementations of the Turkish Social Security Institution. Cost analysis of procedures showed that the total cost of the TVHL group was $34.8 \%$ lower than the HSG group. In conclusion, we found that in patients with a suspected tubal factor problem, beginning with TVHL for the diagnosis and treatment of the problem is less costly than beginning with HSG. In broad case-series, there is a mortality rate of 3.33 for every 100,000 laparoscopies and a total complication rate of 4.64 for every 1000 laparoscopies [19]. In a study composed of 1516 patients who underwent THL, the rate 
of failure due to retroverted uterus and adhesions was reported as $5.4 \%$ and a wide and easy appearance including both ovaries and tubes was reported as $88.3 \%$ [14]. According to these data, THL is seen as a reliable, easy to use and active method [20]. Although it includes very few patient groups in comparison to laparoscopy, the complication rate for THL has been found to be approximately $1.6 \%$ in the literature $[14,21,22]$. The only complication in our series was rectal. Our patient was discharged after double antibiotic treatment for a week and observation in the hospital.

The broadly accepted contradictions for THL are obliterated pouch of Douglas, fixed retroverted uterus, pelvic inflammatory disease, vaginal infection, ovarian mass as well as impossible vaginal operation. Careful vaginal disinfection, a maximum of 3 attempts for accessing the pouch of Douglas, avoiding sexual intercourse and use of a vaginal tampon during the week following the operation and use of prophylactic antibiotic are the precautions for minimizing the complication risk [9].

One of the most important reasons for patients' good tolerance of THL performed under local anesthesia is the vaginal approach and the other one is that the distention environment used is warm ringer/saline solution rather than carbon dioxide. Use of small diameter laparoscopes, not manipulating abdominal organs, no trans-abdominal introduction, and no or little need for Trendelenburg are the major advantages of this technique. Also excess distention due to carbon dioxide, distention, pain and irritation due to the acidic and dry environment caused in abdominal organs are avoided. It is known that carbon dioxide also causes peritoneal irritation itself. Many physiological pneumoperitoneum problems are avoided as there is no carbon dioxide used in the distention environment $[23,24]$. In carbon dioxide pneumoperitoneum, there is also a risk of masking thin membranous adhesions and not noticing vascularization [25]. This is easier due to the dimensional view effect of these thin adhesions, small non-fibrotic endometriotic lesions and neo-angiogenesis with hydroflotation [26].

Similar to previous studies, we observed in our study that THL is an easily applied technique $[3,4,6$, $8,12,14]$. The rate of failure in accessing the pouch of Douglas by THL in the cases in which tubal pathology selection was not made has been reported as $5 \%$, lower levels than the classic culdoscopy technique [4]. Failure in accessing the pouch of Douglas was $10 \%$ in our study. Based on the published data, the reasons for preference of THL over laparoscopy are that THL is a less invasive method that can be applied in office conditions, takes less time, and assesses tubal passage by performing chromopertubation together with THL. Moreover, cost analysis has an important place in method preference. Although the pricing policy of every country is different, there are limited data in the current literature. A total package cost policy is followed in Turkey for such operations (including the operation, anesthesia, and stay at the hospital). According to the cost analysis we made for our patient group, we can say that sequences of diagnostic operations started with THL are more advantageous and cheaper in comparison to the sequences of diagnostic operations started with HSG and diagnostic laparoscopy. This cost analysis can possibly vary according to the health implementations and pricing policies of different countries. However, our study has some limitations. We included a relatively small sample of patients and it needs further studies with larger patient series.

Consequently, for elective patients, THL is preferable compared to HSG. Both are cost-effective, simple and safe. In addition to lower costs, they avoid possible complications, and the time factor and postoperative patient discomfort are improved.

\section{Conclusions}

Transvaginal hydrolaparoscopy, which is the new guide for diagnosis of tubal patency and reproductive organ status, is more effective than HSG, and it also protects the patient from infection and exposure to radiation. Transvaginal hydrolaparoscopy is more cost effective than other procedures in the assessment of infertile patients. The possibility of an operative procedure with THL is limited in comparison to laparoscopy. Transvaginal hydrolaparoscopy can be used as the first stage in place of HSG for daily conditions in the assessment of infertile patients and it can substantially decrease the load of laparoscopy by selecting the patients requiring a real operation. We believe that the need for real operative laparoscopy could be determined by THL. Standard laparoscopy may then not be necessary for every patient but only for patients with pathology detected in HSG. 


\section{References}

1. Miller JH, Weinberg RK, Canino NL, et al. The pattern of infertility diagnoses in women of advanced reproductive age. Am J Obstet Gynecol 1999; 181: 952-7.

2. Vandekerckhove P, Watson A, Lilford R, et al. Water-soluble media for assessing tubal patency with hysterosalpingography or laparoscopy in subfertile women. Cochrane Database Syst Rev 2000; 2: CD000092.

3. Catenacci M, Goldberg JM. Transvaginal hydrolaparoscopy. Semin Reprod Med 2011; 29: 95-100.

4. Gordts S, Campo R, Rombauts L, et al. Transvaginal hydrolaparoscopy as an outpatient procedure for infertility investigation. Hum Reprod 1998; 13: 99-103.

5. www.sgk.gov.tr. 2010 Yılı Sağlık Uygulama Tebliği (SUT) (Notice of Health Implementations).

6. Streda R, Mardesic T, Kult D, et al. The diagnostic value of hysterosalpingography in the diagnosis of tubal disease [Czech] Ceska Gynekol 2009; 74: 18-21.

7. Ahinko-Hakamaa KM, Huhtala $H$, Tinkanen $H$. Confirmation of tubal patency in hysterosalpingo-contrast sonography by transvaginal hydrolaparoscopy. Acta Obstet Gynecol Scand 2009; 88: 286-90

8. Zimmer M, Milnerowicz-Nabzdyk E, Rosner-Tenerowicz A, et al. Transvaginal hydrolaparoscopy for diagnosis of tubal infertility. Neuro Endocrinol Lett 2011; 32: 722-6.

9. Darai E, Dessolle L, Lecuru F, Soriano D. Transvaginal hydrolaparoscopy compared with laparoscopy for the evaluation of infertile women: a prospective comparative blind study. Hum Reprod 2000; 15: 2379-82.

10. Gordts S, Campo R, Puttemans P, et al. Investigation of the infertile couple: a one-stop outpatient endoscopy-based approach. Hum Reprod 2000; 17: 1684-7.

11. Verhoeven H, Gordts S, Campo R, et al. Role of transvaginal hydroloaproscopy in the investigation of female infertility: a review of 1000 procedures. Gynecol Surg 2004; 1: 191-3.

12. Gordts S, Puttemans P, Gordts S, et al. Transvaginal laparoscopy. Best Pract Res Clin Obstet Gynaecol 2005; 19: 757-67.

13. Daraï E, Coutant C, Dessolle L, Ballester M. Transvaginal hydrolaparoscopy. Minerva Chir 2009; 64: 365-72.

14. Daraï E, Coutant C, Dessolle L, Ballester M. Transvaginal hydrolaparoscopy. Minerva Ginecol 2011; 63: 31-8.

15. Evers JL, Land JA, Mol BW. Evidence-based medicine for diagnostic questions. Semin Reprod Med 2003; 21: 9-15.

16. Broeze KA, Opmeer BC, Van Geloven N, et al. Are patient characteristics associated with the accuracy of hysterosalpingographyin diagnosing tubal pathology? An individual patient data meta-analysis. Hum Reprod Update 2011; 17: 293-300.

17. Yang R, Ma C, Qiao J, et al. The usefulness of transvaginal hydrolaparoscopy in infertile women with abnormal hysterosalpingogram results but with no obvious pelvic pathology. Eur J Obstet Gynecol Reprod Biol 2011; 155: 41-3.

18. Waterlot JM, Coutinho EM, Spaniola P, et al. (eds.). Fertiloscopy. In: Reproductive medicine: a milenium rewiev. The proceedings of the $10^{\text {th }}$ World Congress on Human Reproduction 2000; 31: 214-8.
19. Chapron C, Querleu D, Bruhat MA, et al. Surgical complications of diagnostic and operative gynaecological laparoscopy: a series of 29,966 cases. Hum Reprod 1998; 13: 867-72.

20. Kowalczyk D, Guzikowski W, Maczka M, et al. Transvaginal hydrolaparoscopy (THL) in diagnosing infertility. Ceska Gynekol 2006; 71: 408-10.

21. Brosens I, Campo R, Puttemans P, et al. One-stop endoscopy-based infertility clinic. Curr Opin Obstet Gynecol 2002; 14: 397-400.

22. Shibahara H, Shimada K, Kikuchi K, et al. Major complications and outcome of diagnostic and operative transvaginal hydrolaparoscopy. J Obstet Gynaecol Res 2007; 33: 705-9.

23. Taşkın O, Buhur A, Birincioglu M, et al. The effects of duration of $\mathrm{CO} 2$ insufflation and irrigation on peritoneal microcirculation assessed by free radical scavengers and total glutathion levels during operative laparoscopy. J Am Assoc Gynecol Laparosc 1998; 5: 129-33.

24. Martinez ST. Stalter KD, Flipi CJ, et al. An unusual case case of trocar site implantation. Surg Endosc 1998; 12: 992-4.

25. Brosens I, Campo R, Gordts S. Office hydrolaparoscopy for the diagnosis of endometriosis and tubal infertility. Curr Op Obstet Gynecol 1999; 11: 371-7.

26. Laufer MR. Identification of clear vesicular lesions of atypical endometriosis: a new technique. Fertil Steril 1997; 68: 739-40.

Received: 1.05.2013, accepted: 14.10.2013. 